\title{
The Key Technology and Algorithm Design for the Development of Intelligent Examination System
}

\author{
Kai Lu ${ }^{1, a^{*}}$ and Mingrui Chen ${ }^{2, b}$ \\ ${ }^{1}$ Technology department of public safety, Hainan Vocational College of Political Science and Law \\ Haikou, China \\ ${ }^{2}$ College of Information Science \& Technology, Hainan University Haikou, China \\ a294870140@qq.com, b1607885098@qq.com
}

\begin{abstract}
Keywords: Intelligent examination system; Three layer development; Silverlight; Algorithm of generating test paper; Performance analysis algorithm
\end{abstract}

\begin{abstract}
Traditional examination by the teacher to choose, group, organization, after the examination, and then by the examination papers to correct, determine the results. Therefore, many factors, such as the standardization degree, the difficulty degree and the rationality of the evaluation, are more easily influenced by the subjective factors. And traditional examination group, organization, examination paper evaluation, performance analysis, test paper retained heavy workload big, such as task. In addition, the traditional test feedback ability is weak, embodied in an exam paper choose optional the gender is big, and the analysis of the results stay on average, pass the surface level. Some of the existing online examination system to achieve a paperless examination, But in the volume group, and result analysis, the basic is the same as the traditional way. This paper mainly discusses the key technology of the development of the intelligent test system, focusing on generating test paper algorithm design and achievement data mining algorithm for the analysis of the design, so as to improve the system test paper quality and performance analysis for teaching and learning in the future to provide detailed decision analysis.
\end{abstract}

\section{Introduction}

With the rapid development of IT technology and the needs of the examination reform of education industry, people have been deeply aware that using computer online examination will bring great social benefits. In recent years, online examination system has become more and more widely used at home and abroad, and its research is in the ascendant.

Only from the current situation of the examination system at home and abroad, development technology from the application of the C/S framework to the local area network transition to the $\mathrm{B} / \mathrm{S}$ framework based on the internet, they each implements the examination management, rolls, online examination/practice, automatic checking, the test results are simple statistical analysis, and other functions, but the group standard system is not enough and the use of test scores for large data mining analysis is basically not exists [1]. This paper will give the key technology and algorithm design for the development of the intelligent test system.

\section{Selection of Development Platform}

At present, with the rapid development of Internet technology, all kinds of information management systems are basically based on the B/S development model. In this mode, the user interface is achieved through the IE browser, the biggest benefit is that the operation and maintenance is relatively simple, can achieve different people from different locations, different access methods (such as LAN, WAN, Internet/Intranet, etc.) access and operation of common data [2].

At present, programming language based on B/S mode is mainly ASP.NET, PHP, JSP, ASP four kinds of technology. ASP.NET is a product of Microsoft's, to provide the basic structure for the dynamic Web application which is easy to be developed; it is the newest development technology in 
the $\mathrm{B} / \mathrm{S}$ mode at present, it can use $\mathrm{C \#}$ language as the.NET platform development language, at the same time with a strong compiler functions, content and code separation and rich Web control and so on. So, this paper mainly discusses the use of the ASP.NET programming technology in Windows Server $2008+$ SQL Server $2010+$ IIS7.0 + NET Framework 4.0 platform to develop the key technique of intelligent test system and algorithm design [3].

\section{MVC Architecture Design}

$\mathrm{B} / \mathrm{S}$ mode, the user interface is achieved through the browser, only a small part of the transaction on the front end (Browser) Browser implementations, most of the main business is in the server (Server) to achieve, thus forming a MVC three tier architecture, Using MVC three-tier architecture has the advantages of the development.

- When the developers in the development can only focus on the specific layer structure.

- Standardized design.

- Reduce the dependence between layer and layer.

- Replace the implementation of the original level with the new implementation.

- For each layer logic reuse.

This examination system uses three layers B/S system structure to carry on the system design, as shown in Fig. 1.

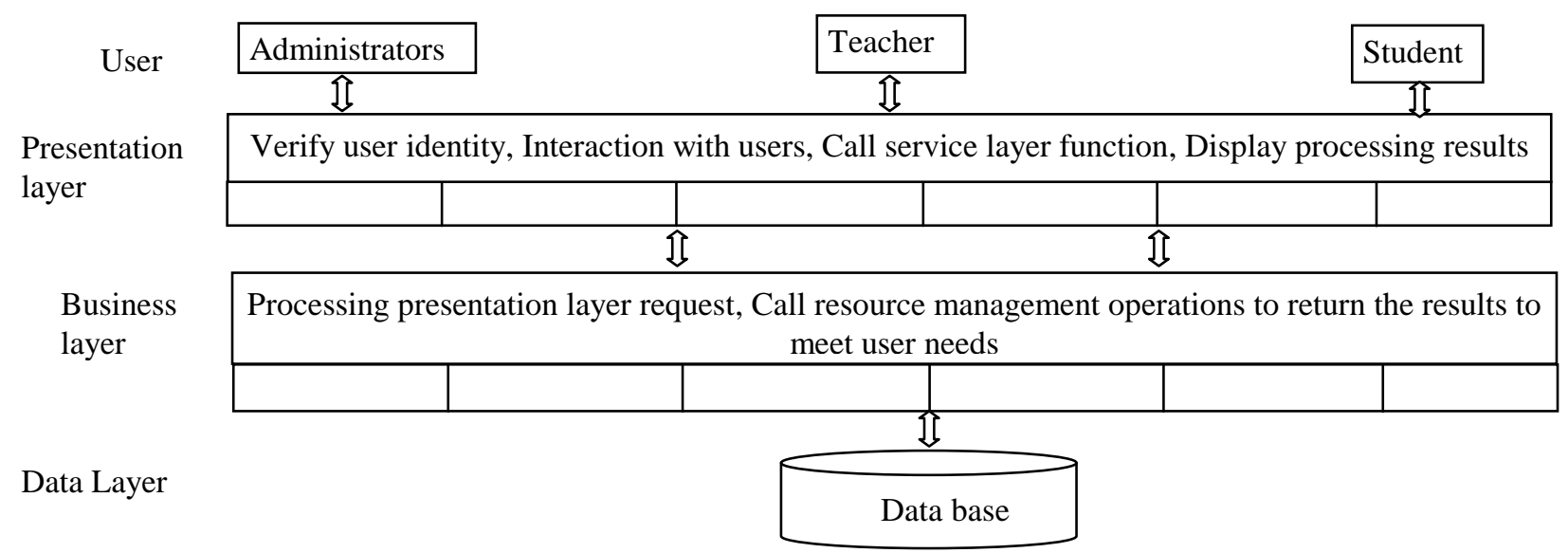

Figure 1. MVC three layer B/S design architecture

Using MVC three-tier B/S architecture development, make the B/S structure of the system has the characteristics of good openness, easy to maintain and extend. The client browser only exchange data with a Web server, data security is quite high. In addition, the three tier architecture model greatly simplifies the computer load on the browser side, reducing the cost and workload of the system maintenance and upgrade, and reduces the user's cost of use [4].

\section{Key Development Technology Design}

Ajax Technology. The intelligent examination system online examination and invigilation is a very important function module, it is of high requirement of system reliability, stability, aimed at this point in this paper, using Ajax technology to solve this problem. In the Ajax model, introduces an Ajax engine between the user and the server, can eliminate the old model of the web "start $\backslash \backslash$ stop start $\backslash$ stop" this interaction process, as it increases the layer mechanism into the program, make the response more sensitive. At the start of the session, the browser loads an Ajax engine, which is written in JavaScript and is usually in a hidden frame. This engine is responsible for drawing the user interface and the communication with the server. Ajax technology allows users to interact with the program in an asynchronous manner, that is to say, do not wait for the server communication, to help users save the waiting time [5]. 
The work of the Ajax model is shown in Fig. 2.

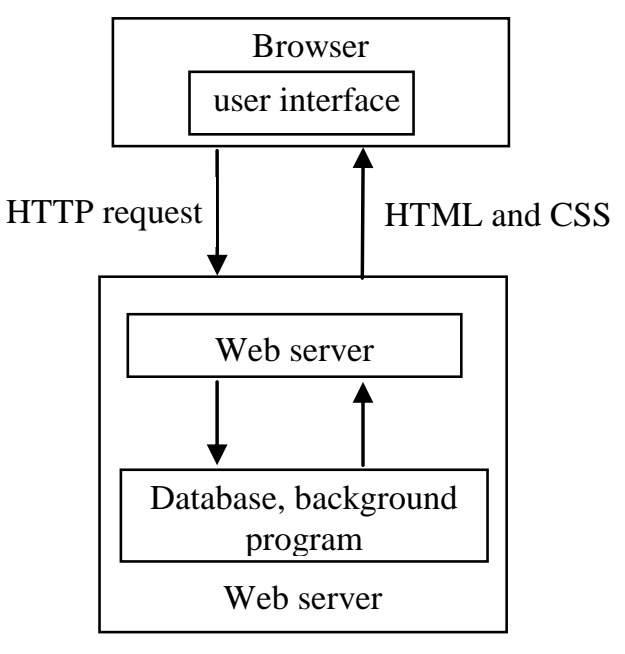

Old Web work mode

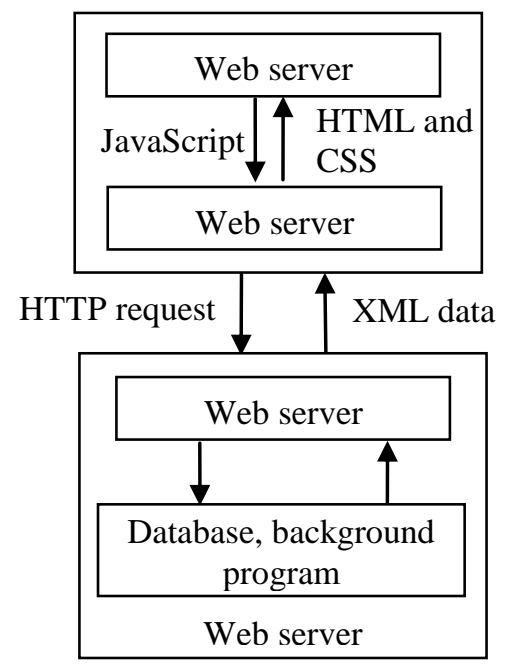

Working mode of Ajax

Figure 2. Working mode of Ajax model

The benefits of using Ajax technology to the system mainly have the following several aspects:

- Using asynchronous way to communicate with the server, do not need to interrupt the user's operation, has more rapid response ability.

- Further promote the separation of the page presentation and data.

- Reduce server load. Ajax is the principle of "on-demand data", you can reduce the maximum redundancy request, reduce the burden on the server.

- Do not refresh the entire page, within the page to communicate with the server.

- Based on standardized and widely supported technology, do not need to download plug-ins or small programs.

- Bring a better user experience.

Due to the Ajax technology has many advantages, in the face of large amount of data during the test to communicate with the server, not only it is not easy to cause loss of data, the phenomenon such as server crashing, and user operations page will smooth many.

Silverlight Plug-in. Regular B/S model development, unable to effectively resolve the interactive access experience between browser and client resources, Such as generating the examinee folder and file written test material and In a transparent way to hand in the examinee answer file to the server. Using cross browser and cross platform Silverlight plug-in technology, it based on ASP. Net and Ajax web development environment to achieve a seamless connection, provides flexible side client programming model, effectively compensate for the restrictions on B / S mode of development [6]. The application created by Silverlight has the following special features:

- It is a cross browser, cross platform technology. It can be run in all common Web browsers, and support in Microsoft Windows and Apple Mac OS X platform.

- It is supported by a very small download program that can be installed within a few seconds.

- It includes a sufficiently clear pattern that the user can operate directly in the browser (drag, rotate, and zoom).

- It reads the data and updates the content, but does not interrupt the user by refreshing the entire page.

- Application can run in a Web browser, you can also configure applications that enable users to run the application on your own computer (outside the browser).

\section{Core Algorithm Design}

Algorithm Design of Generating Test Paper. Intelligent test paper generation algorithm is the core 
of artificial intelligence test paper, the initial test paper algorithm uses the random extraction method or the error compensation algorithm, its efficiency is the highest, but its instability makes it prohibitive for its application. Later on the basis of the random extraction method, and the backtracking test method, it has the highest quality of the test paper, but its low efficiency and the quality of the rarely used. In recent years, Ant colony optimization has obtained some research results, which successfully solved the classic combinatorial optimization problems such as traveling salesman, shop scheduling, and graph coloring and so on. Ant colony optimization has the advantages of strong global optimization ability, group intelligent search, information positive feedback and high robustness, etc. [7].

The ant colony optimization search technology structure with high distinguishability test, Specific approach is to subject of discrimination as heuristic information element, and the introduction of a candidate list, pheromone global and local update and local search strategy, efficient, quickly constructed with high distinguishability, scientific papers, the user can use the technique to construct one or more with high distinguishability of the papers and the organization of the examination[8]. Using ant colony algorithm intelligent test paper working process design as shown in Fig. 3:

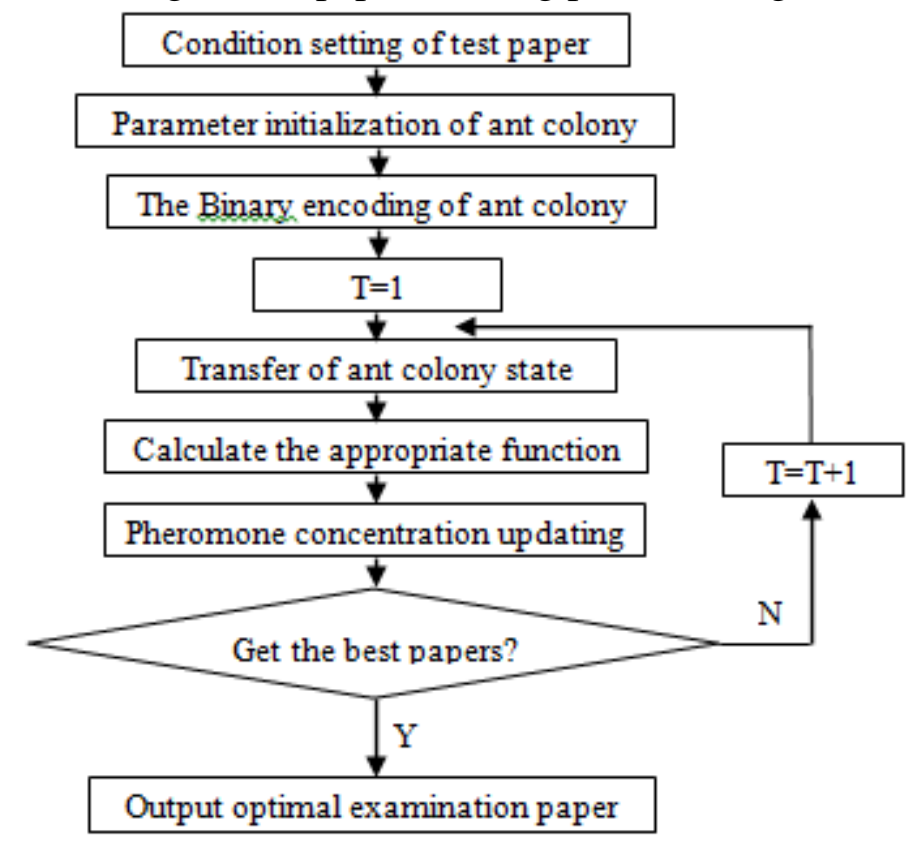

Figure 3. Ant colony algorithm of intelligent test paper work flow

Performance Analysis Algorithm Design. Students' test score information is an important basis for evaluating the quality of teaching, and it is also an important symbol to evaluate students' mastery of knowledge. Therefore, through the analysis of students' scores, it is important for managers to improve the teaching conditions, strengthen the teaching management, deepen the teaching reform and improve the quality of teaching. Data mining is a decision support process, is deep data analysis method, the data mining technology application in predictive analysis of the performance is very useful, it can be a more comprehensive analysis of the correlation between test scores and various factors [9].

C4.5 algorithm is one of the ten classical algorithms of data mining. Its main idea is: Based on the principle of information entropy, The attribute of the maximum information gain is selected as the classification attribute, the structure of the branch of the decision tree is made, and the whole decision tree(As shown in Fig. 4 Student achievement whether to pass decision tree) is constructed in a recursive way. Information gain ratio equals to the ratio of the information gain and the partition information [10].

From Fig. 4 can be seen in the usual results as a decision tree root node attributes, the figure depicts the relationship between student achievements and whether passing grades, attendance and exam review time. And so on, the data mining technology which is formed by this algorithm can be applied 
to the analysis of students' performance, which can provide decision analysis for teaching and learning, thus improving the efficiency of teaching and learning.

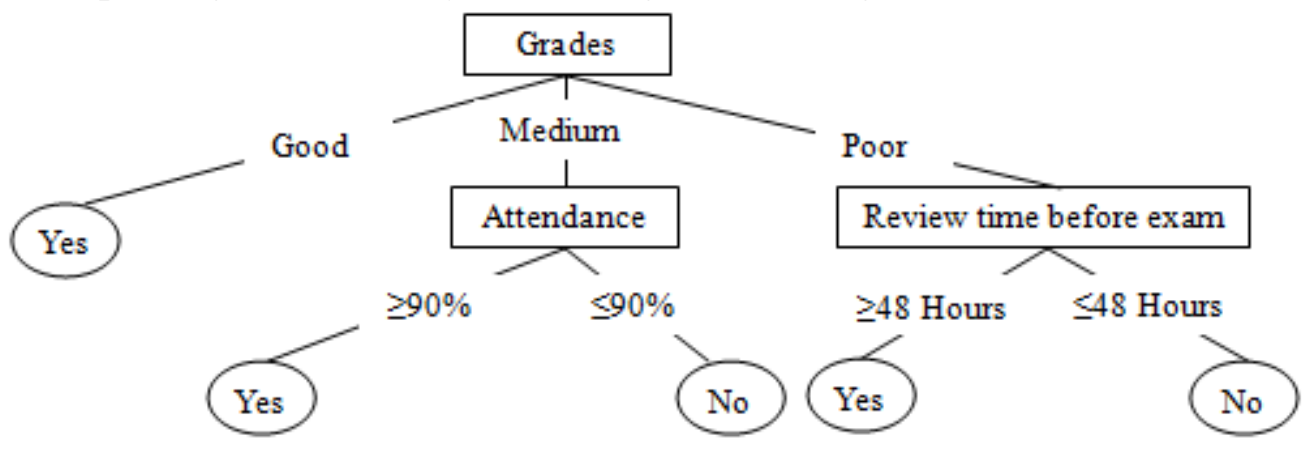

Figure 4. Student achievement whether to pass decision tree

\section{Summary}

In this paper, according to the development of the examination system at home and abroad, The core technology of test system based on ASP.NET4.5+SQL 2012 is designed, Proposed using MVC three layer development framework, Ajax and Silverlight plug-ins and other key technologies, The work flow of intelligent generating test paper of ant colony algorithm is presented and introduce the use of C4.5 algorithm to analyze the big data of the examinee. By using the techniques and algorithms mentioned above, it can improve the reusability, reliability, stability, openness and intelligence of the examination system.

\section{Acknowledgements}

This paper is written for the natural science foundation of Hainan Province. The project name is "The Research and Development of Intelligent Examination System Based on Improved ACO and C4.5 Algorithm", which was applied in 2014 and the project number is 614243.

\section{References}

[1]F. Tang: Research on the development of online examination system and its key technologies (MS., Xi'an University of Technology, China 2014), p.37.

[2]Y.Q. Zhou: The design and implementation of online examination system based on Ajax Technology (MS., Suzhou University, China 2011), p.34.

[3]X.Y. Zhuang: Analysis system of intelligent test paper test and performance management in Higher Vocational Colleges (MS., Shandong University, China 2012), p. 25.

[4]M. Li: The design and implementation of online examination system (MS., Shandong University, China 2013), p.17.

[5]J. Xiao: Research on component development of online examination system and algorithm of generating test paper (MS., Xi'an University of Technology, China 2011), p.29.

[6]Q. Lv: The design and implementation of online examination system (MS., Dalian University of Technology, China 2013), p.22.

[7]W.H. Qi: Research on intelligent examination system model based on ant colony algorithm [J].Computer application research, Vol.30 (2013) No.3, p.205.

[8]R.J. Wu: Research on Application of ant colony algorithm in automatic test paper generation[J]. Computer simulation, Vol.28 (2011) No.8, p.139.

[9]Y.L. Fu: Application of data mining technology $\mathrm{C} 4.5$ algorithm in performance analysis [J]. Journal of Chongqing University of Technology, Vol.29 (2013) No.5, p.161.

[10]H.P. Bain: Application of improved C4.5 algorithm in performance analysis [J].Computer knowledge and technology, Vol.11 (2015) No.27, p.189. 